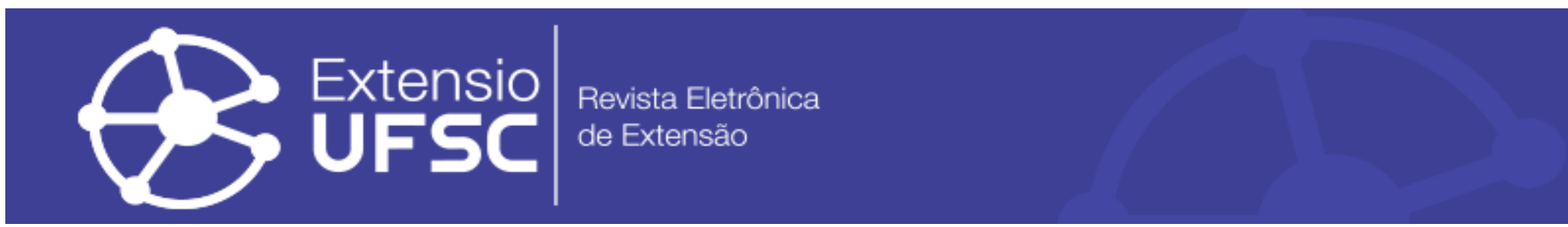

\title{
ATENÇÃO EM SAÚDE BUCAL EM PACIENTES PORTADORES DE SÍNDROME DE DOWN - RELATO DE EXPERIÊNCIA
}

\author{
Glória Maria Linhares Bandeira de Melo Ferreira \\ Universidade Estadual do Piauí \\ gloriabandeiram@gmail.com \\ Ingrid Safira Freitas Silva \\ Universidade Estadual do Piauí \\ ingrid.fs@outlook.com \\ Wanderson Carvalho de Almeida \\ Universidade Estadual do Piauí \\ wangstron@gmail.com
}

\author{
Brenda Castro Rodrigues Ferraz \\ Universidade Estadual do Piauí \\ ferrazbrenda99@gmail.com \\ Maria Ângela Ârea Leão Ferraz \\ Universidade Estadual do Piauí \\ angela.endo@hotmail.com \\ Carlos Alberto Monteiro Falcão \\ Universidade Estadual do Piauí \\ falcaoendo@hotmail.com
}

\section{Resumo}

A promoção de ações de capacitação de acadêmicos para prevenção e promoção de saúde bucal dos pacientes com Síndrome de Down busca proporcionar a melhoria na qualidade de vida dos pacientes e de seus familiares, além de multiplicar a qualificação de futuros profissionais aptos à assistência integral à pessoa com necessidades especiais. O objetivo deste artigo é relatar a experiência, por um período de dois anos, do projeto de extensão Sorrisos Especiais, da Universidade Estadual do Piauí, que atua na APAE de Parnaíba, Piauí. A estratégia usada no projeto foi a orientação dos pacientes assistidos nessa instituição de referência por meio de atividades lúdicas e práticas de escovação supervisionada, a fim de prevenir agravos de saúde bucal. Portanto, conclui-se que a interação universidade-comunidade proporciona condições para o bem-estar global do indivíduo e promove aos acadêmicos a formação de novas habilidades e competências ao acompanhar pacientes portadores da Síndrome de Down.

Palavras-chave: Educação em Odontologia. Síndrome de Down. Saúde Bucal.

\section{ORAL HEALTH CARE IN PATIENTS WITH DOWN SYNDROME - EXPERIENCE REPORT}

\begin{abstract}
The promotion of academic training actions for the prevention and promotion of oral health for patients with Down Syndrome seeks to provide an improvement in the quality of life of patients and their families, in addition to multiplying the qualification of future professionals capable of comprehensive care to the person with special needs. The purpose of this article is to report the experience, for a period of two years, of the extension project Sorrisos Especiais, from the State University of Piauí, which works at APAE in Parnaíba, Piauí. The strategy used in the project was the orientation of patients assisted in this reference institution through playful activities and supervised brushing practices in order to prevent oral health problems. Therefore, it is concluded that the university-community interaction provides conditions for the global well-being of the individual and promotes the formation of new skills and competences for academics when accompanying patients with Down Syndrome.
\end{abstract}

Keywords: Dental Education. Down Syndrome. Oral Health.

\section{ATENCIÓN DE SALUD ORAL EN PACIENTES CON SÍNDROME DE DOWN - INFORME DE EXPERIENCIA}

\footnotetext{
Resumen

La promoción de acciones de capacitación académica para la prevención y promoción de la salud bucal de pacientes con Síndrome de Down busca brindar una mejora en la calidad de vida de los pacientes y sus familias, además de multiplicar la calificación de futuros profesionales capaces de brindar atención integral a la persona. con necesidades especiales El propósito de este artículo es informar la experiencia, por un período de dos años, del proyecto de extensión Sorrisos Especiais, de la Universidad Estatal de Piauí, que trabaja en APAE en Parnaíba, Piauí. La estrategia utilizada en el proyecto fue la orientación de los pacientes asistidos en esta institución de referencia a través de actividades lúdicas y prácticas supervisadas de cepillado para prevenir problemas de salud bucal. Por lo tanto, se concluye que la interacción entre la universidad y la comunidad proporciona condiciones para el bienestar global del individuo y promueve la formación de nuevas habilidades y competencias para los estudiantes cuando acompañan a pacientes con síndrome de Down.

Palavras clave: Educación en Odontología. Síndrome de Down. Salud Bucal.
} 
Atenção em saúde bucal em pacientes portadores de Síndrome de Down - Relato de Experiência

\section{INTRODUÇÃO}

Cerca de $10 \%$ da população mundial é constituída por Portadores de Necessidades Especiais (PNE), são indivíduos que apresentam perda ou anormalidade de uma estrutura do corpo ou função fisiológica, temporária ou permanente, progressiva, regressiva ou estável, requerendo atendimento diferenciado (BRASIL, 2008).

A síndrome de Down (SD) é uma cromossomopatia, ou seja, uma doença cujo quadro clínico global é explicado por um desequilíbrio na constituição cromossômica (no caso, a presença de um cromossomo 21 extra), caracterizando, assim, uma trissomia simples (BRUNONI, 1999) e acarreta complicações clínicas que acabam por interferir no desenvolvimento global da criança portadora, sendo que as mais comumente encontradas são alterações cardíacas, hipotonia, complicações respiratórias e alterações sensoriais, principalmente relacionadas à visão e à audição (BISSOTO, 2005)

O portador de deficiência apresenta inúmeros problemas decorrentes de diferentes bases etiológicas com a probabilidade de ocorrência de distúrbios de comunicação, locomoção e sentido, sendo constantes os problemas de ordem médica e odontológica, que comprometem, sobremaneira, seu bem-estar. Esta realidade tornou premente a necessidade da atuação de uma equipe multiprofissional integrada e especializada (MARTA, 2011). Portanto, torna-se importante a consciência de que a melhor prevenção é aquela que se enquadra nos níveis 1,2 e 3 de Leavell \& Clark, ou seja, a Promoção da Saúde, Proteção Específica, Diagnóstico Precoce e Tratamento Imediato, respectivamente, que atuam antes da instalação do problema (LEAVELL CLARK, 1976; MARTA, 2011).

Os Portadores da Síndrome de Down estão entre os mais comuns pacientes que exigem um atendimento especial diante das consultas odontológicas, porque a síndrome não apenas afeta sua saúde geral como também o seu desenvolvimento craniofacial (AL HABASHNEH et al., 2012). Esses pacientes são mais propensos ao desenvolvimento de doenças orais, pois têm dificuldades para a remoção da placa bacteriana, apresentam um quadro de diminuição do fluxo salivar (xerostomia) e, geralmente, consumem muitos alimentos ricos em açúcar, que aliado à ausência de uma coordenação motora adequada essencial a uma boa higiene bucal, podem apresentar mais experiência de cáries (GIMÉNEZ et al., 2003; RODRÍGUES et al., 2003; ROSENBAUMAND STEWART, 2004; SIQUEIRA et al., 2007; CHU LO, 2010; DU et al., 2010; CARVALHO et al 2011; GRZIC et al, 2011; IHTIJAREVIC-TRTAK et al 2014; RODRÍGUEZ PEINADO et al., 2018). 
Atenção em saúde bucal em pacientes portadores de Síndrome de Down - Relato de Experiência

Uma educação para a saúde de pacientes com necessidade especial deve ser voltada aos pais, cuidadores. Acadêmicos do curso de odontologia podem contribuir com programa de escovação supervisionada com este público-alvo, como forma de incentivar e ressaltar a importância da assistência odontológica precoce aos portadores da síndrome de Down (DE OLIVEIRA GIRO, 2011).

A participação do Cirurgião-Dentista é fundamental para a reabilitação e para a integração desses pacientes dentro da sociedade. A atuação desse profissional da saúde deve ser encorajada, para que o cuidado expedido aos pacientes portadores da síndrome de Down aconteça de maneira integral (PINI, FRÖHLICH e RIGO, 2016) e a extensão universitária exerce um papel que contribui para a formação de futuros dentistas mais atentos às necessidades desse público.

Dessa forma, os objetivos do Projeto de extensão intitulado "Sorrisos Especiais", da Universidade Estadual do Piauí em parceria com a APAE, Associação de Pais e Amigos dos Excepcionais, é firmar estratégias a fim de facilitar o atendimento odontológico às crianças e adolescentes portadores da síndrome de Down e garantir seus direitos básicos. Além de permitir que os estudantes de odontologia da universidade tenham a oportunidade de ampliar suas experiências e habilidades no âmbito social e clínico. Este trabalho visa descrever a experiência dos acadêmicos de odontologia da Universidade Estadual do Piauí (UESPI), que participam do projeto de extensão "Sorrisos Especiais", direcionada ao atendimento de pacientes portadores da Síndrome de Down.

\section{MATERIAIS E MÉTODOS}

O presente artigo trata-se de um relato de experiência de caráter descritivo do Projeto de Extensão “Sorrisos Especiais”, desenvolvido semanalmente, durante os semestres 2018.1 a 2019.2, envolvendo um total de 40 crianças entre 7 e 15 anos de idade.

O projeto é vinculado à Instituição APAE (Associação de Pais e Amigos dos Excepcionais) localizada na cidade de Parnaíba, cidade litorânea localizada a 338 quilômetros da capital Teresina - Piauí, e conta com o envolvimento de oito acadêmicos regularmente matriculados no curso de Odontologia da Universidade Estadual do Piauí, campus Professor Alexandre Alves de Oliveira e de dois professores da instituição. A fim de cumprir os objetivos do projeto, alunos foram divididos em grupos, possibilitando a realização das atividades no centro da instituição especializada nos cuidados de portadores da Síndrome de Down.

Para executar o projeto na instituição de referência, os pais ou responsáveis legais assinaram um termo de consentimento que permitia trabalhar com as crianças de acordo com os métodos 
escolhidos pelos alunos e professores envolvidos no projeto, além de poder ser utilizado para fins didáticos e científicos.

Como proposta de transmissão de conhecimentos, foram realizadas semanalmente orientação dos pacientes assistidos nesta instituição de referência por meio de atividades lúdicas que envolvem apresentações teatrais, músicas e práticas de escovação supervisionada para promoção e prevenção de problemas bucais e encaminhamento, quando necessário, para atendimento na Clínica Escola de Odontologia, inserindo os acadêmicos de odontologia na realidade da assistência do paciente especial. Palestras para pais e responsáveis sobre a importância da prevenção e instruções para o acompanhamento da saúde bucal dos indivíduos especiais também foram realizadas.

As atividades desenvolvidas pelo projeto ainda possibilitaram a identificação de agravos de saúde bucal entre os portadores de Síndrome de Down pelos acadêmicos previamente calibrados que encaminhavam os pacientes com necessidades clínicas para atendimento na Clínica Escola de Odontologia da UESPI/Parnaíba.

\section{RELATOS E ANÁLISES}

Sendo um dos pilares da formação acadêmica, a extensão universitária é um processo educativo, interdisciplinar, científico, cultural e político, no qual transforma e integra a Universidade aos outros setores da sociedade. Suas ações se apresentam para a comunidade como a prática dos conteúdos aprendidos dentro da Universidade pelos alunos e possibilita, durante os anos da graduação, humanizar o futuro profissional, permitindo a vivência extramuros (SENA et al., 2018).

O desenvolvimento do indivíduo portador da Síndrome de Down é, tanto quanto o de qualquer não portador, resultante de influências sociais, culturais e genéticas; incluindo-se aí as expectativas havidas em relação às suas potencialidades e capacidades e os aspectos afetivoemocionais da aprendizagem. (BISSOTO, 2005). A inserção dos acadêmicos de odontologia na extensão universitária, especialmente no projeto "Sorrisos Especiais", permite buscar tanto uma melhoria na qualidade de vida e na saúde bucal dos pacientes portadores da SD através da orientação em saúde bucal e da aplicação de flúor, como também desenvolver habilidades e aptidões nos estudantes para atendimento a esse público-alvo.

O projeto de extensão "Sorrisos Especiais" buscou concretizar etapas. Primeiramente, os encontros foram destinados aos pais ou responsáveis das crianças. e foram ministradas a eles palestras sobre a importância da prevenção e a inclusão dos mesmos nesse processo, bem como o 
detalhamento do projeto, a explicação de seus principais objetivos e o consentimento através da assinatura do termo de consentimento. Dentre todos os envolvidos, apenas uma mãe não assinou o termo e, portanto, não efetuou a sua participação e do seu filho. Verificamos que o fato dessa mãe ser analfabeta a deixou insegura para participar do projeto, apesar do termo de consentimento ter sido lido para ela.

Em encontros posteriores, foi feito o primeiro contato com as crianças, em um momento de descontração destinado à troca de informações de modo a facilitar a prática das etapas seguintes. $\mathrm{Na}$ sequência, introduziu-se uma das grandes ferramentas do projeto, a atividade lúdica, a qual durante o desenvolvimento favorece a expressão, a comunicação e a integração de indivíduos em grupos sociais. O lúdico, durante o atendimento odontológico para pacientes portadores de necessidades especiais, é uma importante ferramenta facilitadora do processo de educação preventivo de doenças bucais, visto que o diálogo descontraído entre o profissional dentista e o paciente especial, o possibilita observar as informações do ambiente e compreender a realidade (OLIVEIRA, 2014). Apesar da maior interação das crianças, percebeu-se a dificuldade de executar as atividades na ausência dos pais.

Desta forma, foram feitas pequenas apresentações teatrais sobre a importância da manutenção da saúde bucal com fantoches que imitavam a escova de dente, o creme dental e o fio dental. Em seguida, iniciou-se a prática de escovação no macromodelo adotando a técnica de escovação de Fones, que é ideal para grupo de pessoas que possuem algum tipo de limitação motora. Paralelo a esse momento, foram produzidas músicas infantis relacionadas à prática da escovação para uma melhor fixação do conhecimento instruído. Essa etapa foi muito produtiva e envolveu a máxima interação das crianças.

A música, quando cantada juntamente com o profissional e equipe, desenvolve um processo socializador. É capaz de desenvolver o raciocínio, elevar a criatividade e proporcionar assimilação de forma mais intensa. É uma atividade lúdica por excelência (MIELE et al., 2000).

A escovação é a forma mais utilizada e socialmente aceita de higiene bucal. No entanto, para tornar-se eficaz no combate à placa bacteriana, a escovação precisa ser orientada e supervisionada pelo profissional, sendo a motivação do paciente fundamental para os melhores resultados. A eliminação da placa bacteriana exige métodos mecânicos de higiene bucal, que têm a necessidade de serem ensinados e treinados com o paciente (VALARELLI et al., 2011).

Durante esse processo, tiveram dias determinados para práticas de escovação supervisionada, nos quais os pacientes puderam desenvolver a técnica de Fones, onde a escova dental é colocada em ângulo reto em relação aos dentes, com movimentos circulares suaves em todas as superfícies dos dentes, com exceção da face mastigatória, na qual são realizados 
Atenção em saúde bucal em pacientes portadores de Síndrome de Down - Relato de Experiência

movimentos ântero-posteriores (PATIL et al., 2014). Esta técnica foi treinada primeiramente no macromodelo. Nesta prática, foi possível a participação dos pais para que pudessem observar e ajudar os filhos de forma correta, e principalmente, reproduzir o passo a passo da técnica em casa.

A última estratégia utilizada no projeto, após essas diversas etapas, consistiu em adaptá-los ao ambiente odontológico através de visitas periódicas ao consultório da instituição a qual fazem parte. No primeiro encontro das crianças com o consultório foi observado uma certa resistência, na maioria, por isso optou-se por utilizar materiais lúdicos novamente, o que permitiu o êxito da atividade. O propósito dessa fase foi facilitar o atendimento e torná-lo menos traumático, possibilitando o condicionamento do comportamento desses pacientes no ambiente do consultório odontológico e tornando o estudante de odontologia uma referência de confiança para eles, algo que foi muito trabalhado dentro do projeto, já que foi uma das principais dificuldades identificadas. As necessidades encontradas foram sanadas na Clínica Escola de Odontologia da UESPI, por alunos participantes do projeto sob supervisão dos professores orientadores.

\section{CONSIDERAÇÕES FINAIS}

O projeto de extensão "Sorrisos Especiais" surgiu com o anseio de minimizar a dificuldade da busca por atendimento odontológico aos portadores da síndrome de Down e buscou englobar uma realidade não vivenciada dentro da universidade. A interação com a comunidade proporciona condições para o bem-estar global dos indivíduos e não só desenvolve habilidades aos acadêmicos de odontologia, como também os torna profissionais sensíveis e mais empáticos em relação à condição de cada paciente.

\section{REFERÊNCIAS}

AL HABASHNEH, R. et al. Oral health status and reasons for not attending dental care among 12- to 16-yer-old children with Down syndrome in special needs centres in Jordan. International Journal of Dental Hygiene, v. 10, n.4, p. 259-264, 2012.

BISSOTO, Maria Luísa. O desenvolvimento cognitivo e o processo de aprendizagem do portador de Síndrome de Down: revendo concepções e perspectivas educacionais. Ciências \& Cognição; v. 4, n. 2, p. 80-88, mar. 2005.

BRASIL. Ministério da Saúde. Secretaria de Atenção à Saúde. Política Nacional de Saúde da Pessoa Portadora de Deficiência. Brasília: Editora do Ministério da Saúde; 2008. (Série E. Legislação em Saúde. 
Atenção em saúde bucal em pacientes portadores de Síndrome de Down - Relato de Experiência

BRUNONI, D. Aspectos epidemiológicos e genéticos. In: SCHWARTZMAN, J. S. Síndrome de Down. p.32-43, São Paulo: Mackenzie, 1999.

CARVALHO, Reyjanne Barros et al. Oral health and oral motor function in Children with cerebral palsy. Special Care in Dentist, v.31, n. 2, p. 58-62, 2011.

CHU C. H. et al. Oral health status of Chinese teenagers with cerebral palsy. Community Dental Health, v. 27, n. 4, p. 222-6, 2010.

DE OLIVEIRA, Ana Luísa Botta Martins; GIRO, Elisa Maria Aparecida. Importância da abordagem precoce no tratamento odontológico de pacientes com necessidades especiais. Odonto, v. 19, n. 38, p. 45-51, 2011.

DU, Rennan Y. et al. Oral health in preschool children with cerebral palsy: a case-control community-based study. International Journal of Paediatric Dentistry, v. 20, n. 5, p. 330-335, 2010.

GIMÉNEZ-PRATS, M. J.; LÓPEZ-JIMENEZ J.; BOJ-QUESADA J. R. An epidemiological study of caries in a group of children with cerebral palsy. Medicina oral: organo oficial de la Sociedad Espanola de Medicina Oral y de la Academia Iberoamericana de Patologia y Medicina Bucal, v. 8, n. 1, p. 45-50, 2003.

GRZIC, Renata et al. Dental health and dental care in children with cerebral palsy. Collegium Antropologicum, v. 35, n. 3, p. 761-764, 2011.

IHTIJAREVI-TRTAK，KOBAŠLIJA S，HADŽAGI-ATIBUŠI F，HUSEINBEGOVI A. Periodontal status in the permanent dentition of children with cerebral palsy. Stomatološkivjesnik, v. 3, n. 1, p. 51-8, 2014.

LEAVELL, H.R.; CLARK, E.G. Medicina preventiva. São Paulo: McGraw-Hill; 1976.

MARTA, Sara Nader. Programa de assistência odontológica ao paciente especial: uma experiência de 13 anos. RGO. Revista Gaúcha de Odontologia (Online), v. 59, n. 3, p. 379-385, 2011.

MIELE, G. M. S. et al. Música e motivação na odontopediatria. Jornal Brasileiro de Odontopediatria e Odontologia do Bebê, Curitiba, v. 3, n. 15, p. 414-423, 2000.

OLIVEIRA, Julisse Carla Cunha. Atividades lúdicas na Odontopediatria: uma breve revisão da literatura. Revista Brasileira de Odontologia, v. 71, n. 1, p. 103, 2014.

PATIL S.P.; PATIL P.B.; KASHETTY MV. Effectiveness of different tooth brushing techniques on the removal of dental plaque in 6-8 year old children of Gulbarga. Journal of International Society of Preventive \& Community Dentistry, v. 4, n. 2, p. 113-116, Maio 2014.

PINI, Danielle de Moraes; FRÖHLICH, Paula Cristina Gil Ritter; RIGO, Lilian. Oral health evaluation in special needs individuals. Einstein (Sao Paulo), v. 14, n. 4, p. 501-507, $2016 .$.

RODRIGUES, M. T. et al. Oral conditions in children with cerebral palsy. Journal of dentistry for children (Chicago, Ill.), v. 70, n. 1, p. 40-46, 2003. 
Atenção em saúde bucal em pacientes portadores de Síndrome de Down - Relato de Experiência

RODRÍGUEZ PEINADO, N. et al. A study of the dental treatment needs of special patients: cerebral paralysis and Down syndrome. European journal of paediatric dentistry, v. 19, p. 233, 2018.

ROSENBAUM P, STEWART D. The World Health Organization international classification of functioning, disability and health (ICF): a model to guide clinical thinking, practice and research in the field of cerebral palsy. SeminPediatrNeurol, 2004; v. 11, p. 5-10, 2004.

SENA, Valéria Sena et al. Prevenção de cárie em crianças do Piauí: um relato de experiência. Extensio UFSC: Revista Eletrônica de Extensão, v. 15, n. 30, p. 140-146, 2018.

SIQUEIRA, Walter Luiz et al. The influence of valproic acid on salivary $\mathrm{pH}$ in children with cerebral palsy. Special Care in Dentistry, v. 27, n. 2, p. 64-66, 2007.

VALARELLI, F. P. et al. Importância dos programas de educação e motivação para saúde bucal em escolas: relato de experiência. Odontol. Clín.-Cient., v.10, n.2, p. 173-176, 2011.

Recebido em: 21/05/2020

Aceito em: 07/07/2021 